\title{
Laminar Localization and Projection-Specific Properties of Presubicular Neurons Targeting the Lateral Mammillary Nucleus, Thalamus, or Medial Entorhinal Cortex
}

\author{
(-1)Li-Wen Huang, ${ }^{1, *}$ (D) Jean Simonnet, ${ }^{1, *}$ Mérie Nassar, ${ }^{1,2}$ Louis Richevaux, ${ }^{2}$ Roxanne Lofredi, ${ }^{1}$ and \\ (1)Desdemona Fricker ${ }^{1,2}$
}

${ }^{1}$ Inserm U1127, CNRS UMR7225, UPMC Université Paris 6 UMR S1127, Institut du Cerveau et de la Moelle Epinière, Sorbonne Universités, Paris 75013, France, and ${ }^{2}$ CNRS UMR 8119, Université Paris Descartes, France

\section{Visual Abstract}

\section{Presubicular output neurons}

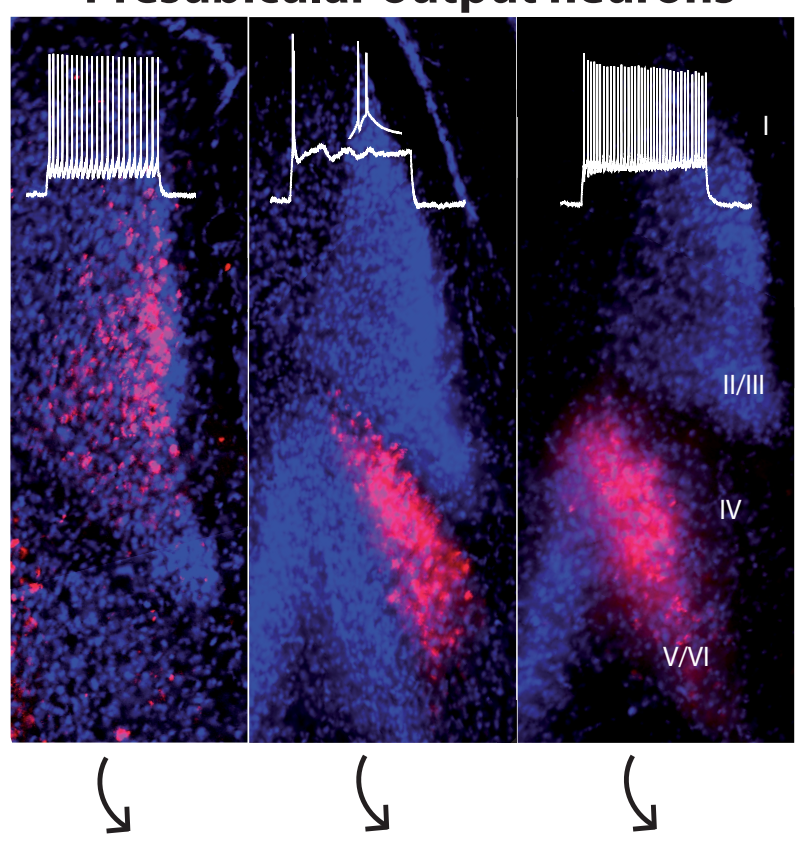

Medial Entorhinal Lateral Mammillary Anterior Thalamic Cortex Nucleus Nucleus
The presubiculum (PrS) is part of an interconnected network of distributed brain regions where individual neurons signal the animals heading direction. PrS sends axons to medial entorhinal cortex (MEC), it is reciprocally connected with anterior thalamic nuclei (ATNs), and it sends feedback projections to the lateral mammillary nucleus (LMN), involved in generating the head direction signal. The intrinsic properties of projecting neurons will influence the pathway-specific transmission of activity. Here, we used projection-specific labeling of presubicular neurons to identify MEC-, LMN-, and ATN-projecting neurons in mice. MEC-projecting neurons located in superficial layers II/III were mostly regular spiking pyramidal neurons, and we also identified a Martinotti-type GABAergic neuron. The cell bodies of LMNprojecting neurons were located in a well-delimited area in the middle portion of the PrS, which corresponds to layer IV. The physiology of LMN projecting, pyramidal neurons stood out with a tendency to fire in bursts of action potentials (APs) with rapid onset. These properties may be uniquely adapted to reliably transmit visual landmark information with short latency to upstream LMN. Neurons projecting to ATN were located in layers $\mathrm{V} / \mathrm{VI}$, and they were mostly regular spiking pyramidal neurons. Unsupervised cluster analysis of intrinsic properties suggested distinct physiological features for the

\section{Significance Statement}

The presubiculum (PrS) is part of a brain wide network of head direction cells. It contributes to the generation of grid cell activity in the downstream medial entorhinal cortex (MEC), and it also feeds back information to subcortical input regions. Here, we identify projection-specific subpopulations of presubicular neurons. We show how they differ in their morphology, laminar location and in their electrophysiological tuning. Distinct presubicular cell types may provide specific coding capacities for distinct output channels of PrS. 
different categories of projection neurons, with some similarities between MEC- and ATN-projecting neurons. Projection-specific subpopulations may serve separate functions in the PrS and may be engaged differently in transmitting head direction related information.

Key words: cell morphology; electrical properties; head direction; patch clamp; postsubiculum; retrograde tracing

\section{Introduction}

Spatial navigation relies on extended brain circuits, including the hippocampal and parahippocampal network that support grid cell (Hafting et al., 2005), place cell (O'Keefe and Nadel, 1978), and head direction cell firing (Taube, 2007). The head directional signal first appears subcortically, in the reciprocally connected dorsal tegmental nucleus and lateral mammillary nucleus (LMN; Bassett et al., 2007; Clark and Taube, 2012). Vestibular sensory information crucially contributes to its generation (Stackman and Taube, 1997; Yoder and Taube, 2014). The head direction signal is then conveyed sequentially to the anterior thalamic nuclei (ATNs; Blair et al., 1998) and the dorsal part of the presubiculum (PrS; also termed postsubiculum; van Groen and Wyss, 1990a; Goodridge and Taube, 1997; Peyrache et al., 2015). In addition to thalamic head direction inputs, the PrS also receives inputs from visual cortex and retrosplenial cortex (Vogt and Miller, 1983; van Groen and Wyss, 1990a; Jones and Witter, 2007; Sugar and Witter, 2016). Self-motion and visual cues continually update the head direction signal (Taube, 2007), and when available, visual landmarks control the preferred firing direction (Zugaro et al., 2003).

It has been shown recently that the transmission of the head direction signal from the ATN is necessary for the generation and function of the grid cell activity in the medial entorhinal cortex (MEC; Winter et al., 2015). The presubicular projection may be essential for serially transferring the head direction signal from the ATN to the medial entorhinal grid cell system (Rowland et al., 2013; PrestonFerrer et al., 2016). Other known projection targets of the PrS include feedback projections to the thalamus (van Groen and Wyss, 1990a,b; Ishizuka, 2001) and LMN (Allen and Hopkins, 1989; Gonzalo-Ruiz et al., 1992). Neurons of

Received December 14, 2016; accepted April 24, 2017; First published April 28, 2017.

The authors declare no competing financial interests.

Author contributions: J.S. and D.F. designed research; L.-W.H., J.S., M.N., and R.L. performed research; L.-W.H., L.R., and D.F. analyzed data; L.-W.H., J.S., and D.F. wrote the paper.

This work was supported by the ANR-10-JCJC-1406 (to D.F.) and the Centre National des Etudes Spatiales (to L.R.).

${ }^{*}$ L. -W.H. and J.S. contributed equally to this work.

Acknowledgements: We thank Dr. Richard Miles, who assisted with discussions, laboratory space, and ressources for the completion of this project, and Yuchio Yanagawa for making available GAD67-GFP mice.

Correspondence should be addressed to either of the following: Desdemona Fricker, M.D., Ph.D., CNRS UMR8119 Université Paris Descartes, 45 Rue des Saints-Pères, 75006 Paris, France, E-mail: desdemona.fricker@parisdescartes.fr; or Jean Simonnet, Ph.D., Bernstein Center for Computational Neuroscience, Humboldt University Berlin, 10115 Berlin, Germany, E-mail: jean.simonnet@bccnberlin.de.

DOI:http://dx.doi.org/10.1523/ENEURO.0370-16.2017

Copyright (C) 2017 Huang et al.

This is an open-access article distributed under the terms of the Creative Commons Attribution 4.0 International license, which permits unrestricted use, distribution and reproduction in any medium provided that the original work is properly attributed. the presubicular microcircuit projecting to these two subcortical areas, ATN and LMN, have been identified as two nonoverlapping populations (Yoder and Taube, 2011). While head direction cells have been recorded in vivo across superficial and deep layers of PrS (Boccara et al., 2010; Tukker et al., 2015; Preston-Ferrer et al., 2016), the physiologic properties of presubicular cells that project to key areas of the head direction system, namely the upstream LMN and ATN, and the downstream MEC, have remained unclear.

In this study, we examine the morphology and physiology of retrogradely labeled presubicular neurons projecting to MEC, ATN, and LMN. We identify parameters that may have a significant influence on the function of presubicular efferent neurons. Principal component analysis (PCA) suggests a distinct profile of intrinsic properties of presubicular LMN-projecting neurons.

\section{Materials and Methods}

\section{Animals}

Experiments were performed on 22 male and female young adult C57BL/6 wild-type mice (postnatal day P29P35 for stereotaxic injection and P31-P40 for recording), as well as six GAD67-GFP mice and two Sst ${ }^{\mathrm{CRE}}$ ::tdTomato mice (Nassar et al., 2015). Animal care and use conformed to the European Communities Council Directive of 2010 (2010/ 63/EU) and French law (87/848). Our study was approved by the local ethics committee Charles Darwin N ${ }^{\circ} 5$.

\section{Stereotaxic injections}

Retrograde fluorescent tracers (Retrobeads, Lumafluor) were injected unilaterally into MEC, LMN, or ATN. Stereotaxic coordinates were: MEC, $-4.65,3.08,-4 \mathrm{~mm}$; LMN, $-2.8,0.75,-5.35 \mathrm{~mm}$; ATN, $-0.8,0.75,-3.2 \mathrm{~mm}$ (anteroposterior, mediolateral, dorsoventral to bregma). The procedure for injections followed a standard protocol (Mathon et al., 2015). Briefly, mice were deeply anesthetized with a mixture of ketamine and xylazine $(80-20 \mathrm{mg} / \mathrm{kg})$. A total of $150-300 \mathrm{nl}$ of Retrobeads were injected with a Hamilton syringe at a speed of $40-60 \mathrm{nl} / \mathrm{min}$. The animals were allowed to recover for at least $48 \mathrm{~h}$.

\section{Slice electrophysiology}

Horizontal slices $(300-320 \mu \mathrm{m})$ containing PrS were prepared from mice that had been previously injected with Retrobeads. The cutting solution contained $125 \mathrm{mM} \mathrm{NaCl}$, $25 \mathrm{mM}$ sucrose, $2.5 \mathrm{mM} \mathrm{KCl}, 1.25 \mathrm{mM} \mathrm{NaH}_{2} \mathrm{PO}_{4}, 25 \mathrm{mM}$ $\mathrm{NaHCO}_{3}, 2.5 \mathrm{mM}$ glucose, $0.5 \mathrm{mM} \mathrm{CaCl} 2$, and $7 \mathrm{mM}$ $\mathrm{MgCl}_{2}$ (cooled to $2-6^{\circ} \mathrm{C}$, bubbled with $95 \% \mathrm{O}_{2} / 5 \% \mathrm{CO}_{2}$ ). Slices were incubated for $15 \mathrm{~min}$ at $36^{\circ} \mathrm{C}$ in a holding chamber with aCSF composed of $124 \mathrm{mM} \mathrm{NaCl}, 2.5 \mathrm{mM}$ $\mathrm{KCl}, 10 \mathrm{mM} \mathrm{NaH}{ }_{2} \mathrm{PO}_{4}, 26 \mathrm{mM} \mathrm{NaHCO}_{3}, 11 \mathrm{mM}$ glucose, $2 \mathrm{mM} \mathrm{CaCl}_{2}$, and $2 \mathrm{mM} \mathrm{MgCl}_{2}$ (bubbled with $95 \% \mathrm{O}_{2} / 5 \%$ $\mathrm{CO}_{2}$ ). After incubation, slices were stored at room temperature. For whole-cell recordings, slices were bathed in 
Table 1. Intrinsic properties of projection-specific presubicular neurons

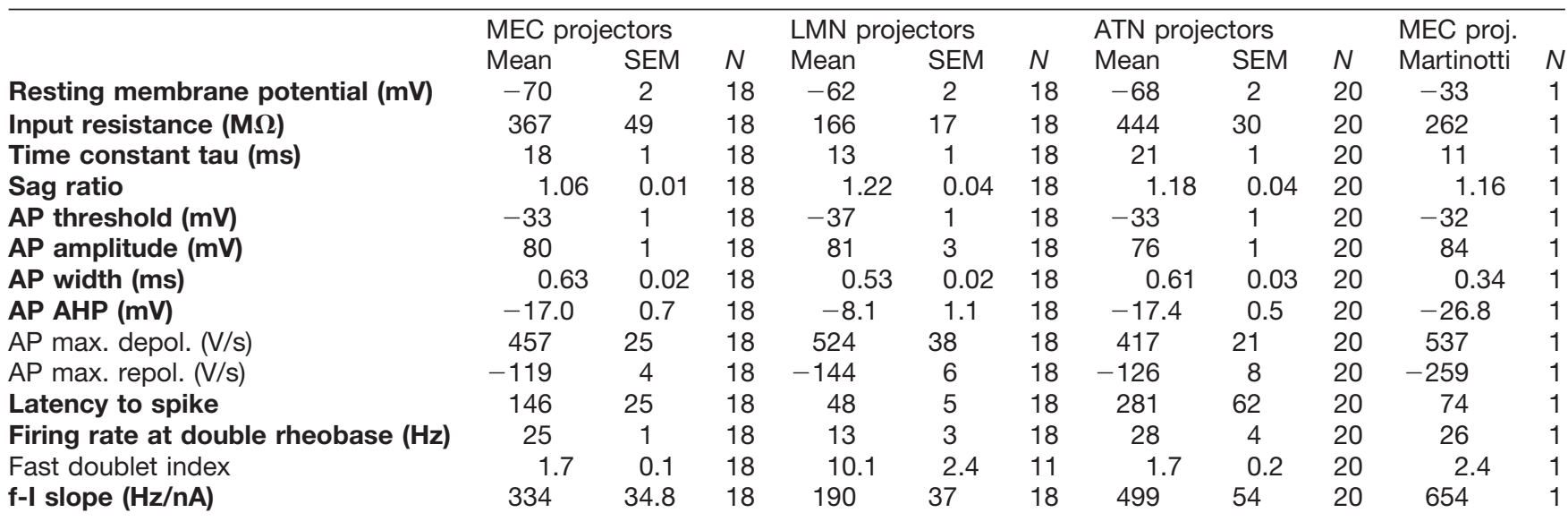

The parameters in bold are used for PCA and cluster analysis in Figure 4.

carbogenated aCSF at $32-34^{\circ} \mathrm{C}$. Retrobeads containing neurons of PrS were identified under a Axioscope 2FS plus microscope (Zeiss), equipped with appropriate LED illumination (Cairn). Pipettes were pulled into patch electrodes with 4- to 6-M $\Omega$ resistance and filled with a potassium-based intracellular solution, $\mathrm{pH}$ 7.3, composed of $140 \mathrm{mM} \mathrm{K}$-gluconate, $1.2 \mathrm{mM} \mathrm{KCl}, 10 \mathrm{mM}$ HEPES, 0.2 mM EGTA, 2 mM MgCl $2,4 \mathrm{mM} \mathrm{MgATP} \cdot 2 \mathrm{H}_{2} \mathrm{O}, 0.4 \mathrm{mM}$ $\mathrm{Na}_{3} \mathrm{GTP} \cdot 2 \mathrm{H}_{2} \mathrm{O}$, and $10 \mathrm{mM}$ Na phosphocreatine. Biocytin ( $3 \mathrm{mg} / \mathrm{ml}$ ) was added for post hoc revelation of cellular morphology. Pipette capacitance was compensated. Electrophysiological signals were sampled at $50 \mathrm{kHz}$ and filtered at $5-6 \mathrm{kHz}$ (Multiclamp 700B or Axopatch 200A amplifier, Molecular Devices) in whole-cell current-clamp mode. Data acquisition and analysis were performed, respectively, in pClamp (Molecular Devices), Axograph, and MATLAB.

The resting membrane potential was determined in voltage-follower mode shortly after breaking in and averaging the membrane potential over $20 \mathrm{~s}$. During the step current injection protocol, baseline membrane potential was maintained at $-65 \mathrm{mV}$. Membrane responses in current clamp were elicited by injecting hyperpolarizing to depolarizing current steps of $800-\mathrm{ms}$ duration (typically starting at $-300 \mathrm{pA} ; 10-20 \mathrm{pA}$ increments). The membrane voltage was plotted as a function of current commands, and a linear fit was created between -70 and -60 $\mathrm{mV}$, the slope of which indicated input resistance, $R_{\text {input }}$. The membrane time constant, tau, was calculated by fitting a double exponential function to an averaged membrane response to a small negative current (potential difference $\Delta V<10 \mathrm{mV}$; Golowasch et al., 2009). The shorter of the two time constants was used. Sag ratio was measured by averaging the ratio $\Delta \mathrm{V}_{\min } / \Delta \mathrm{V}_{\text {steady-state }}$ of three data points around $-100 \mathrm{mV}\left(\Delta \mathrm{V}_{\min }=\mathrm{V}_{\min }-\right.$ $\left.\mathrm{V}_{\text {baseline }} ; \Delta_{\text {steady-state }}=\mathrm{V}_{\text {steady-state }}-\mathrm{V}_{\text {baseline }}\right)$.

The properties of the first action potential (AP) at rheobase (the minimal current required to discharge APs) were characterized: AP threshold (a point at the foot of the AP where $\mathrm{dV} / \mathrm{dt}>30 \mathrm{~V} / \mathrm{s}$ ), AP amplitude (from threshold to peak), AP width (width at half-maximum amplitude), afterhyperpolarization amplitude (AHP, from threshold to the trough of the AHP), and AP maximum depolarization and repolarization rates. The latency of the first AP was measured from the onset of the rheobase current step to the peak of the AP. The firing rate at twice rheobase was determined. The current step that gave the AP firing rate closest to $15 \mathrm{~Hz}$ was analyzed for bursting behavior of spiking, quantified by fast-doublet index (the averaged interspike interval over the first interval, only applicable for neurons that fired more than two spikes during positive current steps). Firing rate increases were quantified by calculating the initial (four to five current points from rheobase) slope of the frequency-current relationship ( $f-I$ slope).

\section{Histology and anatomy}

Slices were fixed in $4 \%$ paraformaldehyde in $0.1 \mathrm{M}$ phosphate buffer (PB) overnight, then incubated with a blocking solution $(2 \%$ milk in PB supplemented with $0.3-1 \%$ Triton X-100). Streptavidin-Cy3 or Cy5 conjugate (1:500; Life Technologies) was used for biocytin staining, and DAPI (1:1000) to stain nuclei. Sections were imaged using a pseudo-confocal Olympus IX81 microscope, and Volocity software for analysis, or a Zeiss LSM 710 confocal microscope. Retrobeads-labeled MEC-projecting neurons of the PrS were visualized in stacks of confocal images of NeuN-stained $60-\mu \mathrm{m}$ sections and counted manually, in four ipsilateral and three contralateral sections from two mice. Their laminar distribution was quantified in each section (total $100 \%$ per section). Retrobeads labeled GABAergic neurons were counted in three sections from one GAD67-GFP mouse and from one SstCre:: tdTomato mouse. The Neurolucida software was used for 3-D computer-aided morphologic reconstruction of biocytin-filled neurons as in (Simonnet et al., 2013).

\section{Statistical analysis}

The PCA and Ward's unsupervised cluster analysis (Ward, 1963; Simonnet et al., 2013) of presubicular projection neurons was implemented using MATLAB, and based on 11 electrophysiological parameters (Table 1): resting membrane potential, input resistance, tau, sag ratio, AP threshold, AP amplitude, AP width, AP AHP, AP 
latency, firing rate at double rheobase, $\mathrm{f}-\mathrm{I}$ slope. Measurements for each variable $x_{i}$ in our data set were transformed to standard scores across all cells based on the formula $\left(\left[\left(x_{i}-\right.\right.\right.$ mean $\left.) / S D\right]$; Romesburg, 1984). To avoid artificially weighting highly correlated variables, the AP maximum depolarization rate and repolarization rate were not included, because they were highly correlated with AP amplitude and AP width, respectively $(r>0.8$ in the correlation matrix), and their value was lower in the PC loadings table (Tsiola et al., 2003).

\section{Results}

\section{Anatomic segregation of LMN, ATN, and MEC projectors in the PrS}

Retrograde fluorescent tracer was injected in MEC (10 mice), LMN (9 mice), or ATN (7 mice), to identify presubicular projection neurons. Injection sites were confirmed post hoc in horizontal sections for MEC (Fig. 1A), and in coronal sections for LMN (Fig. 1B) and ATN (Fig. 1C). MEC injection targeted the superficial layers of the $\mathrm{MEC}$, and in some cases deep layers were also hit. Cases where MEC injections were not entirely restricted to the MEC were excluded from analysis. LMN injection sites and ATN injection sites were confirmed in three cases by slicing the rostral half of the brain in the coronal plane, while the distribution of retrogradely labeled neurons was observed in horizontal sections of PrS, contained in the caudal half of the brain (Fig. 1, illustrations).

Retrobeads injection into MEC resulted in bilateral retrograde labeling in the PrS. Both ipsi- and contralaterally, labeled neurons were most numerous in presubicular layer III, some were located in layer II, and some in deep layers (Fig. 1D). Retrobeads-labeled neuron counts resulted in highest numbers in layer III (ipsi, 686 cells, $55 \pm$ $8 \%$; contra, 258 cells, $57 \pm 4 \%$ ), and in layer II (ipsi, 213 cells, $33 \pm 7 \%$; contra, 116 cells, $41 \pm 7 \%$ ). A total of 50 cells $(6 \pm 2 \%)$ were Retrobeads-labeled in ipsilateral layer IV and 23 cells in contralateral layer IV ( $2 \pm 2 \%), 41$ cells $(6 \pm 4 \%)$ in ipsilateral layer $\mathrm{V} / \mathrm{Vl}$, and 9 cells $(1 \pm 1 \%)$ in contralateral layer V/VI (total ipsilateral, 990 cells in four slices; total contralateral, 406 cells in three slices). Retrobeads-labeled neuron somata were also observed in other brain regions known to project to the MEC, including the parasubiculum, subiculum, CA1 and postrhinal cortex, which underscores the specificity and efficacy of our retrograde tracing. Following Retrobeads injection into LMN, labeled neurons were located in the ipsilateral $\mathrm{PrS}$, in a well-defined area in the center portion of presubicular layers. This area corresponded to the cytoarchitectonic limits of layer IV (Fig. 1E). No beads-labeled neuron somata were observed in layers I-III, nor in V/VI. Following ATN injection, Retrobeads-labeled neurons were found in the deep portion of the ipsilateral PrS, in layers V/VI (Fig. 1F), but not in superficial layers I-III nor in layer IV. The home layers of LMN- and ATN-projecting neurons were closely adjacent and we consider the labeling of somata of these two projecting neuron populations as defining the limits of presubicular layers IV versus V/VI, respectively (Yoder and Taube, 2011).
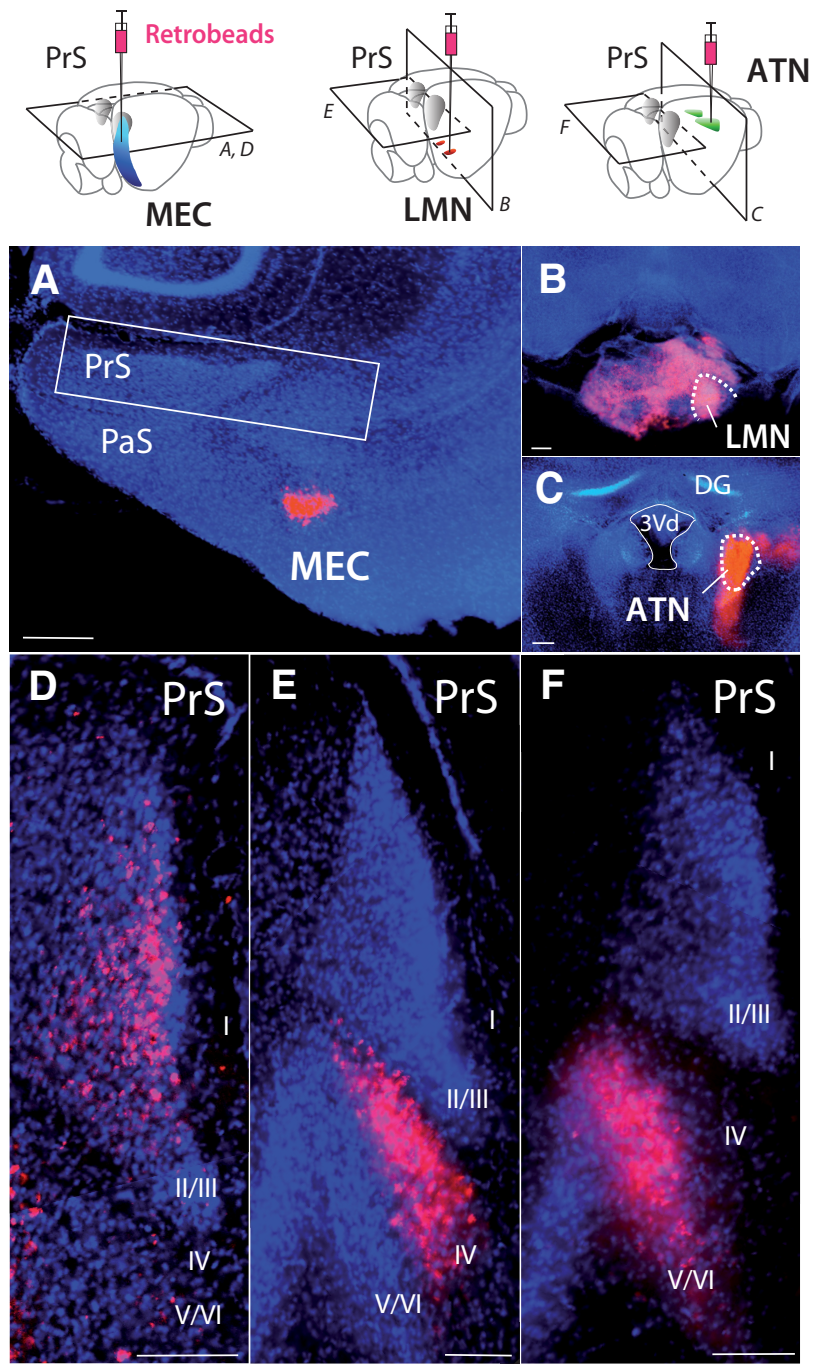

MEC projectors

LMN projectors

ATN projectors

Figure 1. Anatomic segregation of presubicular neurons that project to MEC, LMN, or ATN. A, Injection of retrobeads into layer III of MEC. Low-magnification image of a horizontal section of the temporal lobe. $\boldsymbol{B}$, Injection of retrobeads into LMN (coronal section). C, Injection of retrobeads into ATN (coronal section). $\boldsymbol{D}$, Higher-magnification image of the PrS (rectangle in $\boldsymbol{A}$ ). Retrogradely labeled MEC-projecting neurons are mostly found in superficial layers of PrS. $\boldsymbol{E}$, LMN-projecting neurons are confined to layer IV of PrS (horizontal section, same animal as in $\boldsymbol{B}$ ). $\boldsymbol{F}$, ATN-projecting neurons are present in layers V-VI of PrS (horizontal section, same animal as in C). Retrobeads in red, DAPI staining in blue. PaS, parasubiculum; DG, dentate gyrus; $3 \mathrm{Vd}$, dorsal third ventricle. Scale bars, $200 \mu \mathrm{m}(\boldsymbol{A}-\boldsymbol{C})$ and $100 \mu \mathrm{m}$ $(\boldsymbol{D}-\boldsymbol{F})$.

\section{Morphology and intrinsic electrophysiological properties of presubicular projecting neurons}

Retrogradely labeled presubicular neurons projecting to MEC, LMN, or ATN were targeted for in vitro whole-cell recordings. The injection sites into MEC or ATN were routinely checked in horizontal sections in all animals used for electrophysiology. LMN was not contained in horizontal slices, but, following our results from anatomic analysis, LMN injections were estimated to be correct, if 


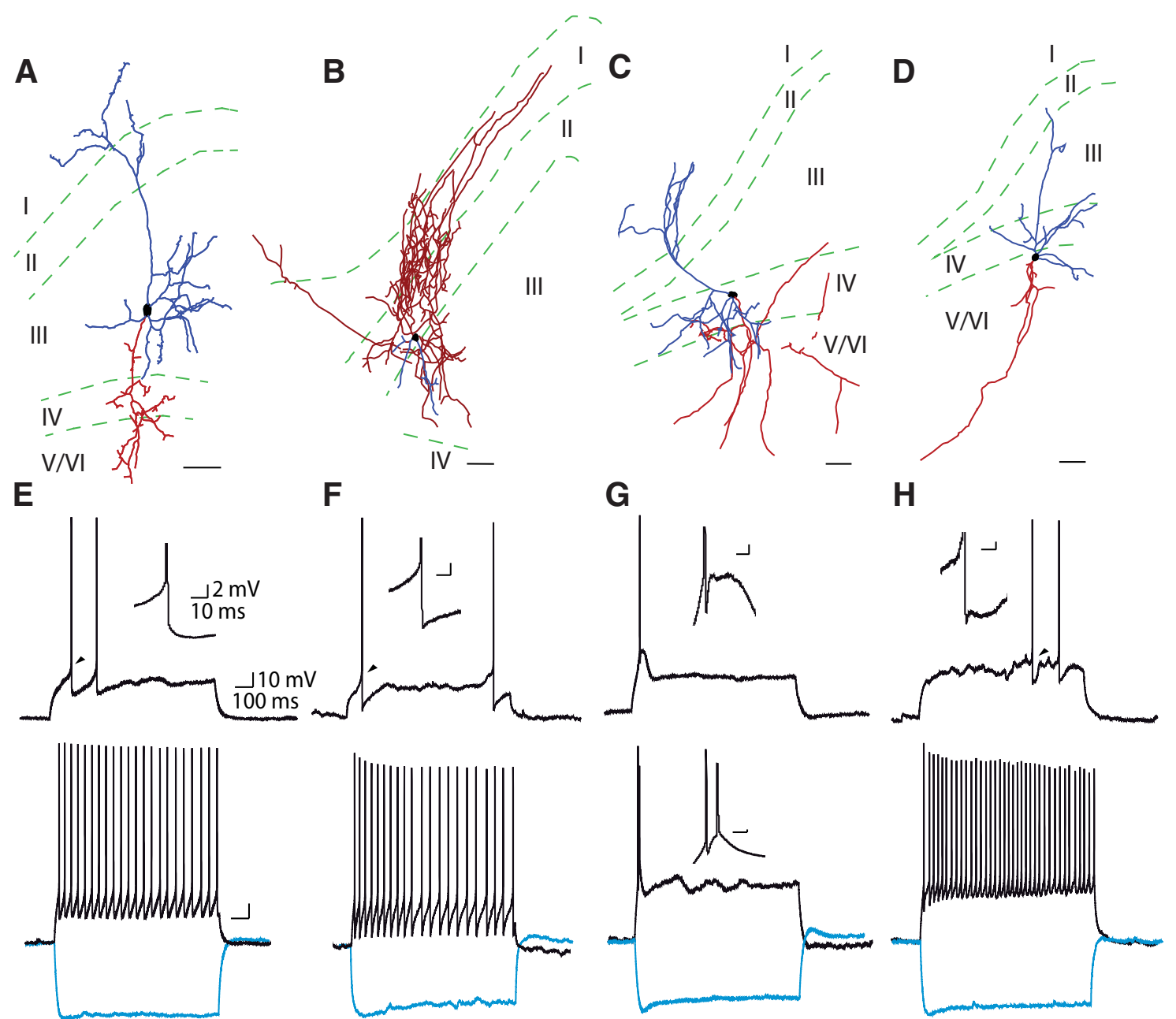

Figure 2. Morphology and firing patterns of retrogradely labeled presubicular projecting neurons. $\boldsymbol{A}$, E, MEC-projecting pyramidal neuron. $\boldsymbol{B}, \boldsymbol{F}, \mathrm{MEC}$-projecting Martinotti interneuron. $\boldsymbol{C}, \boldsymbol{G}$, LMN-projecting neuron. $\boldsymbol{D}, \boldsymbol{H}, \mathrm{ATN}$-projecting neuron. $\boldsymbol{A}-\boldsymbol{D}$, Reconstruction of cell morphology with dendrites in blue and axons in red. Scale bars, $50 \mu \mathrm{m}$. Additional examples of reconstructions of presubicular projection neurons can be found in Extended Data Fig. 2-1. $\boldsymbol{E}-\boldsymbol{H}$, Firing patterns at rheobase (upper traces) and at double rheobase (lower traces). Membrane voltage responses to hyperpolarizing current steps of -150 pA are shown in light blue. Insets show larger scale traces of the first AP.

labeled neurons were present specifically and exclusively in layer IV of PrS. Active spiking behavior and passive membrane properties of 57 projecting neurons were measured and quantified. Table 1 gives an overview of mean \pm SEM of all measured parameters. Figure 2 shows an illustrative example of morphology and electrophysiology for each group of projecting neurons (more examples are included as Extended Data, Fig. 2-1). Graphs in Figure 3 give all data points for all parameters, and statistical comparisons between the different groups of projecting neurons

\section{MEC projectors in superficial layers: regular spiking pyramidal neurons or interneurons}

We recorded from 19 retrogradely labeled presubicular MEC-projecting neurons, which were all located in superficial layers. A total of $5 / 19$ were located close to the border of layer II/III, the other $14 / 19$ in layer III. No deep layer MEC-projecting neurons were recorded. Reconstruction of dendritic and axonal morphologies of recorded and biocytin filled MEC-projecting neurons revealed that they were mostly typical layer III pyramidal neurons, with apical dendrites arborizing in layer I, basal dendrites in layer III, and axons branching across deep layers. A total of $90 \%$ of mean dendritic length was distributed across layers I-III (Figs. 2A, 2-1; Tables 2, 3). Interestingly, one Retrobeadslabeled MEC-projecting neuron in layer III was nonpyramidal and identified as a putative long-range projecting GABAergic neuron with a typical Martinotti type morphology (Fig. 2B). The axon of the Martinotti cell arborized densely in superficial layers and its dendrites extended across deep layers.

Pyramidal MEC-projecting neurons had a mean resting membrane potential of $-70 \pm 2 \mathrm{mV}(n=18)$. Following positive current injections, they fired at high frequencies with little adaptation ( $n=18$; Fig. $2 E$ ). The firing frequency at double rheobase current in pyramidal MEC projectors was $25 \pm 1 \mathrm{~Hz}$, significantly higher than in LMN projectors $(13 \pm 3 \mathrm{~Hz} ; p<0.05$; Fig. $3 F)$. Negative current injections revealed very little voltage sag. The sag ratio was $1.06 \pm$ 
A

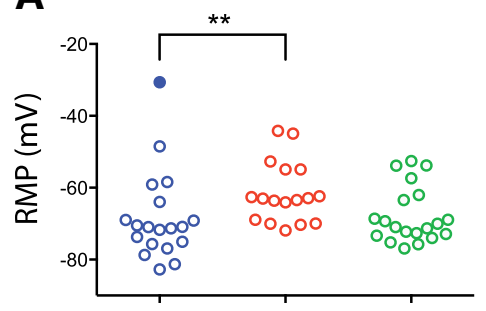

D

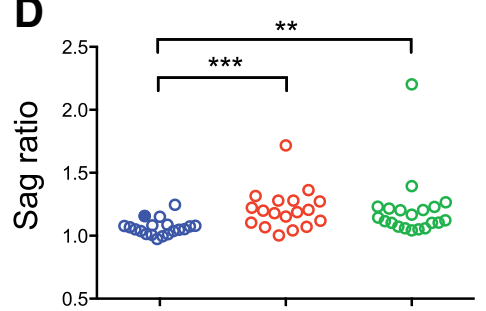

G
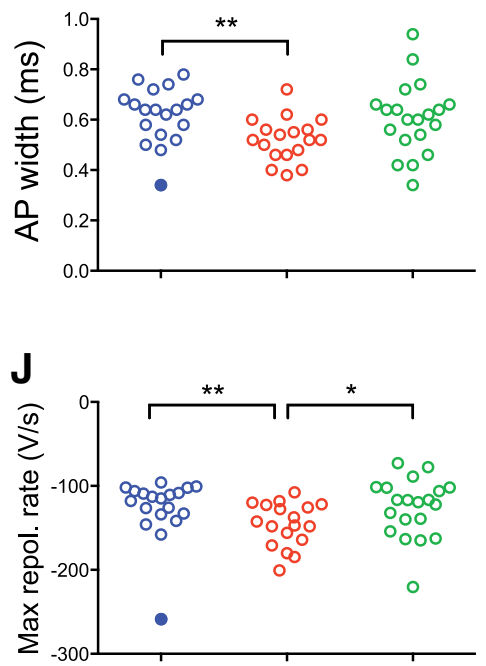

M

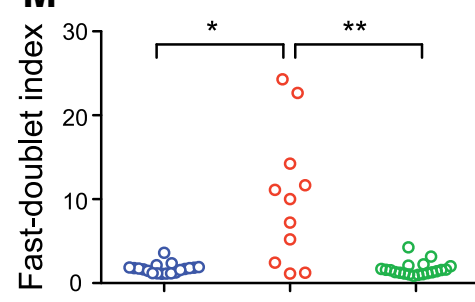

MEC LMN ATN
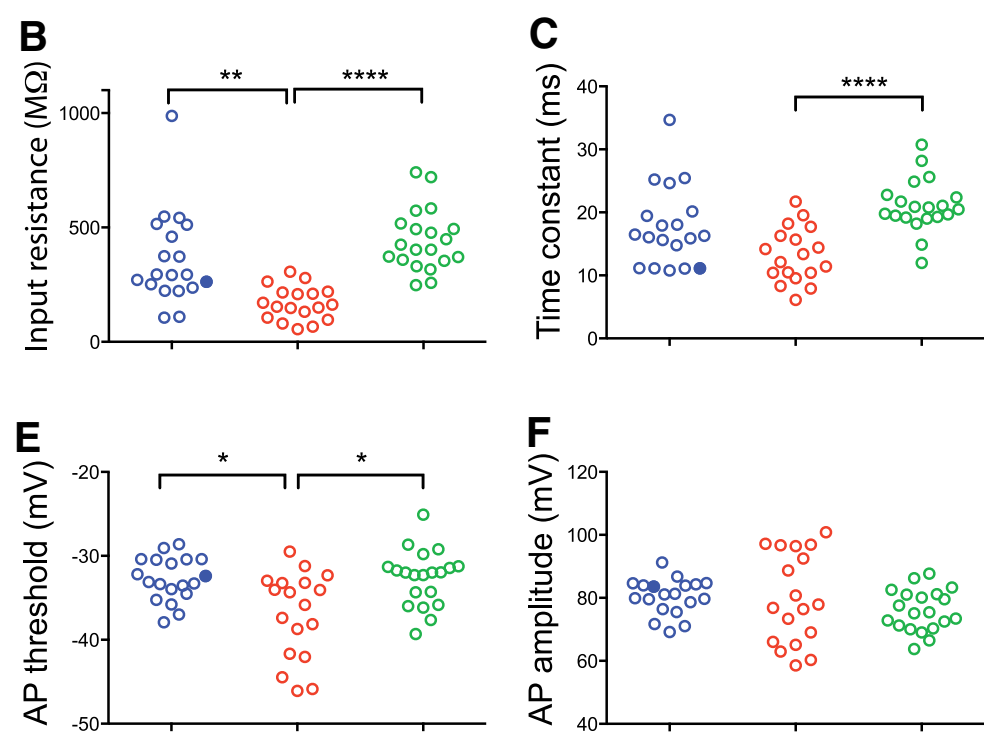
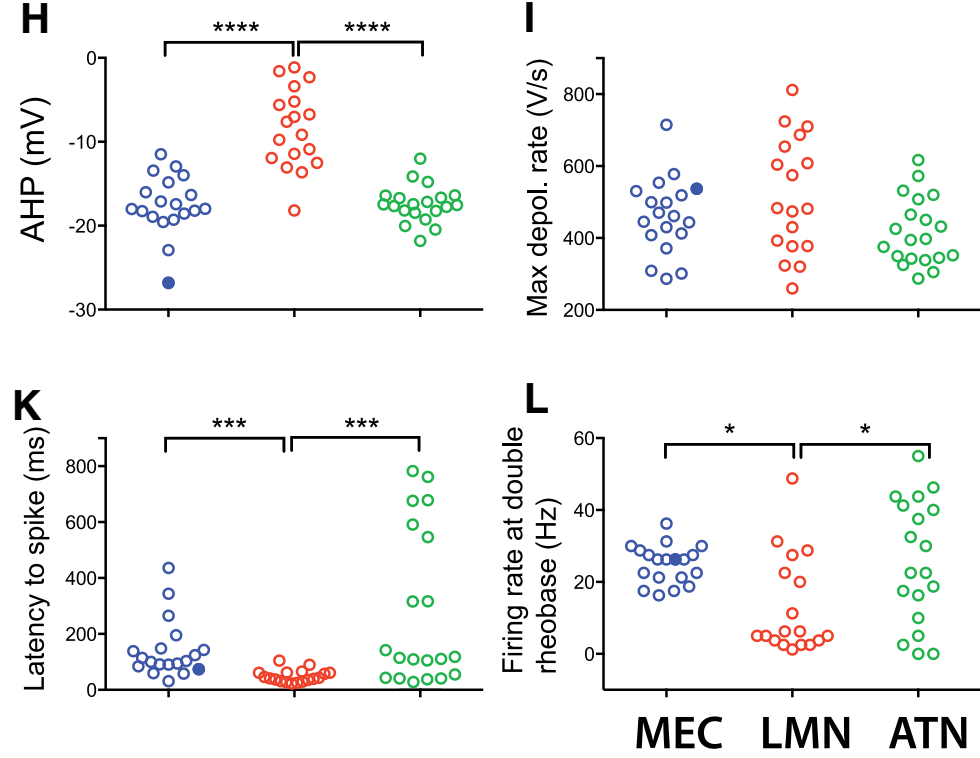

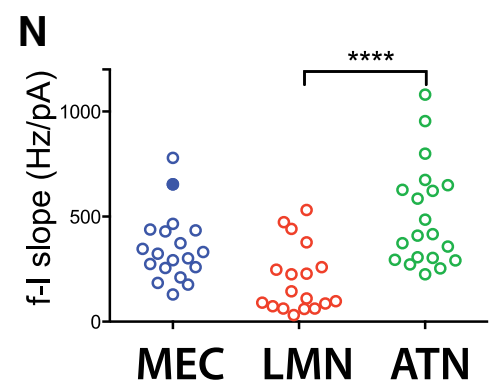

Figure 3. Comparison of intrinsic properties of presubicular neurons that project to MEC (blue), LMN (red), or ATN (green). A, Resting membrane potential (RMP). B, Input resistance. $\boldsymbol{C}$, Time constant. $\boldsymbol{D}$, Sag ratio. $\boldsymbol{E}$, AP threshold. $\boldsymbol{F}$, AP amplitude. $\boldsymbol{G}$, AP width. $\boldsymbol{H}$, AHP. I, AP maximum depolarization rate. $\boldsymbol{J}$, AP maximum repolarization rate. $\boldsymbol{K}$, Latency to first spike at rheobase. $\boldsymbol{L}$, Firing rate at double rheobase. $\boldsymbol{M}$, Fast doublet index. $\boldsymbol{N}$, f-I slope. Kruskal Wallis and Dunn's multiple comparison post hoc test were performed for significance among projecting neurons, $* p<0.05, * * p<0.01, * * * p<0.001, * * * * p<0.0001$. Data for one MEC projecting Martinotti-type interneuron are represented as filled blue circles in the graphs, but they are not included for the statistical comparison among the groups of MEC-, LMN-, or ATN-projecting neurons. 
Table 2. Dendritic layer length of projection-specific presubicular neurons

\begin{tabular}{|c|c|c|c|c|c|c|c|c|c|}
\hline & \multicolumn{3}{|c|}{$\begin{array}{l}\text { MEC } \\
\text { projectors }\end{array}$} & \multicolumn{3}{|c|}{$\begin{array}{l}\text { LMN } \\
\text { projectors }\end{array}$} & \multicolumn{3}{|c|}{$\begin{array}{l}\text { ATN } \\
\text { projectors }\end{array}$} \\
\hline & Mean & SEM & $N$ & Mean & SEM & $\mathrm{N}$ & Mean & SEM & I \\
\hline aye & 447 & 163 & 8 & 319 & 122 & 8 & 24 & 17 & \\
\hline & 126 & $3 \varepsilon$ & 8 & 75 & 16 & 8 & 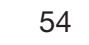 & 27 & \\
\hline _ay & 1144 & 246 & 8 & 407 & 77 & 3 & 174 & 6 & \\
\hline _ay & 144 & 98 & 8 & 802 & 134 & 8 & 433 & 206 & 1 \\
\hline _aye & 2 & 2 & 8 & 616 & 134 & 8 & 617 & 131 & 1 \\
\hline$(\mu \mathrm{m})$ & 50 & 42 & 8 & 196 & 106 & 8 & 340 & 245 & $t$ \\
\hline Total $(\mu \mathrm{m})$ & 1911 & 335 & 8 & 2415 & 266 & 8 & 1643 & 354 & 7 \\
\hline
\end{tabular}

Figure 2-1 shows corresponding biocytin reconstructions of projection neurons.

0.01 , significantly smaller than in LMN or ATN projectors $(p<0.001$ and $p<0.01$, respectively; Fig. $3 D)$. The latency to the first spike for rheobase current injections was $146 \pm 25 \mathrm{~ms}$, significantly longer than for LMN projectors, but not significantly different from ATN projectors $(p<0.001$ and n.s., respectively; Fig. 3; Table 1).

Voltage recordings of the MEC projecting Martinotti type interneuron are shown in Figure $2 F$. Its intrinsic properties are given in Table 1, and data points appear as filled blue circles in the graphs in Figure 3. We observed spontaneous AP firing from a depolarized membrane potential (average membrane potential, $-33 \mathrm{mV}$ ) with prominent AP AHPs. The AHP amplitude was $-26.8 \mathrm{mV}$ in this MEC projecting Martinotti cell, deeper than the average AHP in pyramidal MEC-projecting neurons $(-17.0 \pm 0.7 \mathrm{mV}$; Fig. $3 H$ ). Its sag ratio was 1.16 , slightly higher than average for the pyramidal MEC-projecting neurons. The Martinotti cell AP width was $0.34 \mathrm{~ms}$, well below the width of pyramidal MEC-projecting neurons ( $0.63 \pm 0.02 \mathrm{~ms}$; Fig. $3 G)$. AP threshold, amplitude and firing rate at double rheobase were close to average pyramidal MEC projectors (Fig. $3 E, F, L)$

To examine whether presubicular GABAergic neurons regularly participate in the projection to MEC, Retrobeads were injected in MEC in transgenic mice where all GABAergic neurons (GAD67-GFP line) or a subpopulation of somatostatin-expressing neurons (SstCre::tdTomato line) can be identified by their green or red fluorescence. We found that six GABAergic presubicular neurons in one GAD67-GFP mouse and six presubicular tomato-expressing

Table 3. Axonal layer length of projection-specific presubicular neurons

\begin{tabular}{|c|c|c|c|c|c|c|c|c|c|}
\hline & \multicolumn{3}{|c|}{$\begin{array}{l}\text { MEC } \\
\text { projectors }\end{array}$} & \multicolumn{3}{|c|}{$\begin{array}{l}\text { LMN } \\
\text { projectors }\end{array}$} & \multicolumn{3}{|c|}{$\begin{array}{l}\text { ATN } \\
\text { projectors }\end{array}$} \\
\hline & Mean & SEM & $N$ & Mean & SEM & $N$ & Mean & SEM & \\
\hline ay & 0 & 0 & 8 & 0 & 0 & 8 & 0 & 0 & \\
\hline 0 & 10 & 10 & 8 & - & 0 & 8 & & & \\
\hline ) & 213 & 67 & 8 & 77 & 71 & 8 & & 0 & \\
\hline & 57 & 78 & 8 & 333 & 136 & 8 & 0 & 0 & \\
\hline Laye & 223 & 113 & 8 & 506 & 166 & 8 & 248 & 60 & \\
\hline 0 & 296 & 294 & 8 & 215 & 180 & 8 & 477 & 109 & \\
\hline otal $(\mu \mathrm{m})$ & 899 & 400 & 8 & 1131 & 295 & 8 & 725 & 125 & \\
\hline
\end{tabular}

Figure 2-1 shows corresponding biocytin reconstructions of projection neurons. neurons in one SstCre::tdTomato mouse also contained Retrobeads. Overall, $<1 \%$ of MEC-projecting neurons were GABAergic. Retrobeads-labeled GABAergic neurons are thus a small minority of presubicular MECprojecting neurons. Due to small sample size, we did not include the unique recording of a MEC projecting Martinotti cell in subsequent PCA or cluster analysis.

\section{LMN projectors: bursting pyramidal neurons in layer IV}

A total of 18 presubicular LMN-projecting neurons were recorded and biocytin filled. All were layer IV neurons with pyramidal shape, an apical dendrite arborizing in layer I (except for one inverted pyramid; Fig. 2-1), basal dendrites mainly in layer IV and V/VI (58\% of mean dendritic length), and their axon branching across deep layers (Figs. 2C, 2-1; Tables 2, 3). The average resting membrane potential of LMN-projecting neurons was $-62 \pm 2$ $\mathrm{mV}$, significantly more depolarized than in the group of pyramidal MEC projectors ( $p<0.01$; Fig. $3 A$ ), and they had a low input resistance $(166 \pm 17 \mathrm{M} \Omega ; p<0.0001$ compared with ATN projectors; Fig. 3B). Following positive current injections, LMN projectors tended to fire in an initial burst of two spikes with short latency $(48 \pm 5 \mathrm{~ms}$, $n=18$; Figs. 2G, $3 K$ ). The first spike at rheobase occurred at significantly shorter latency than in either MEC or ATN projectors $(p<0.001)$. Short latency AP firing in LMN projectors was favored by a short membrane time constant, significantly shorter than in ATN projectors (tau, $13 \pm 1 \mathrm{~ms} ; p<0.0001$; Fig. $3 C$ ). We also note the presence of a depolarizing current at the onset of a depolarizing step (Fig. 2G) promoting short latency firing of either bursts or single spikes. After the initial discharge, cells could fire regular sparse APs. A depolarizing envelope always underlay the first spike, and the amplitude of the AHP was low $(-8.1 \pm 1.1 \mathrm{mV}$, compared with -17.4 $\pm 0.5 \mathrm{mV}$ for ATN or $17.0 \pm 0.7 \mathrm{mV}$ for pyramidal MECprojecting neurons; $p<0.0001$; Fig. $3 H$ ), evidence for the ability to fire bursts (Connors and Gutnick, 1990; Simonnet et al., 2013). The bursting tendency was quantified by the fast-doublet index, which was $10.1 \pm 2.4$ for LMN projectors ( $n=11)$, while MEC projectors $(n=18)$ and ATN projectors $(n=20)$ both had very low average fastdoublet indices of $1.7 \pm 0.1$ and $1.7 \pm 0.2$ (Fig. 3M). Most LMN projectors displayed prominent sag during negative current steps, and rebound depolarization after the offset (Fig. 2G). The sag ratio was $1.21 \pm 0.28(n=18)$, significantly higher than in pyramidal MEC projectors $(p<$ 0.001; Fig. 3D).

\section{ATN projectors: regular firing pyramidal neurons in layer $\mathbf{V} / \mathbf{V}$}

A total of 20 presubicular ATN-projecting neurons were recorded. They were deep layer neurons with pyramidal shape, as the example in Figure 2D. Dendrites distributed across all layers, with $69 \%$ of mean dendritic length in layers IV and V/VI. The axons ran through deep layers V/VI to exit PrS (Figs. 2D, 2-1; Tables 2, 3). The mean resting membrane potential of ATN-projecting neurons was $-68 \pm 2 \mathrm{mV}(n=20$; Fig. $2 H)$, similar to MEC-projecting neurons. Values for mean input resistance $(444 \pm 30 \mathrm{M} \Omega$ ) 
and membrane time constant ( $21 \pm 1 \mathrm{~ms})$ were high, and both parameters were significantly higher than in LMN projectors $(p<0.0001$; Fig. $3 B, C)$. The latency to spike was long at rheobase in some cells, but not in all cells (average late ncy, $281 \pm 62 \mathrm{~ms}$ ). For larger current injections, ATN projectors fired with little adaptation $(n=20$; Fig. $2 H$ ). For negative current injections, ATN-projecting neurons showed a large sag (sag ratio, $1.18 \pm 0.04$; Fig. $3 D$ ), which appeared somewhat slower compared with LMN-projecting neurons (Fig. 2G,H). The AP width in ATN projectors was $0.61 \pm 0.03 \mathrm{~ms}$, with a slower maximum repolarization rate compared with LMN projectors $(p<$ 0.05; Fig. 3J).

\section{Physiologic segregation of projection-specific presubicular neurons}

We next wished to examine the range of intrinsic properties of presubicular projection neurons (Fig. $4 A$ ) using PCA. PCA selected variables that contributed most to the overall variability and, thus, were most important in distinguishing different physiologic cell groups. The first PC (PC1) captured most of the variability (34\%). The parameters that were positively correlated with PC1 included passive properties, tau and input resistance, and active properties, $f-I$ slope, firing rate at double rheobase, AP width, AP threshold, latency to spike. PC2 mostly correlated with sag ratio, $f-I$ slope, firing rate at double rheobase, and PC3, mostly AP width, capturing an additional $15.9 \%$ and $14.7 \%$ of the total variability, respectively. Thus, $\sim 64.6 \%$ of the total variability could be explained by the first three PCs. PCA revealed a separation between LMN-projecting neurons (Fig. 4B, red dots) and ATN/ MEC-projecting neurons (Fig. $4 B$, green dots/blue dots). The same data set was then submitted to unsupervised cluster analysis. The projection-specific subpopulations of neurons are reflected in the dendrogram as two major clusters, separating LMN projectors (Fig. 4C, red) from MEC projectors (Fig. 4C, blue) and ATN projectors (Fig. $4 C$, green). The two subclusters in the LMN projecting group corresponded to two subpopulations in PCA as well. ATN-projecting neurons were separated into two different subclusters with one subcluster sharing some similarity with MEC-projecting neurons.

\section{Discussion}

We have examined projection-specific subpopulations of presubicular neurons in the mouse. MEC, LMN, and ATN-projecting neurons largely segregate anatomically in their layer distribution and also physiologically in their intrinsic properties. Presubicular LMN projectors form a population with unique properties: they are pyramidal neurons located in layer IV, characterized by intrinsic bursting discharge behavior and short latency firing. Presubicular ATN-projecting neurons are found in deep layers V/VI. They are anatomically apart from LMN projectors, and their regular spiking firing pattern also distinguishes them from LMN projectors. The large majority of
A

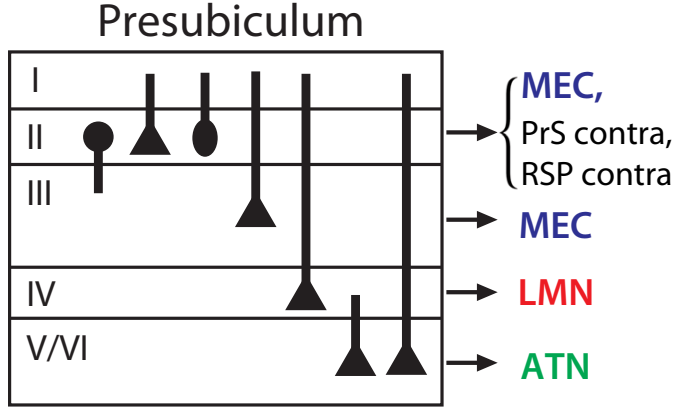

B

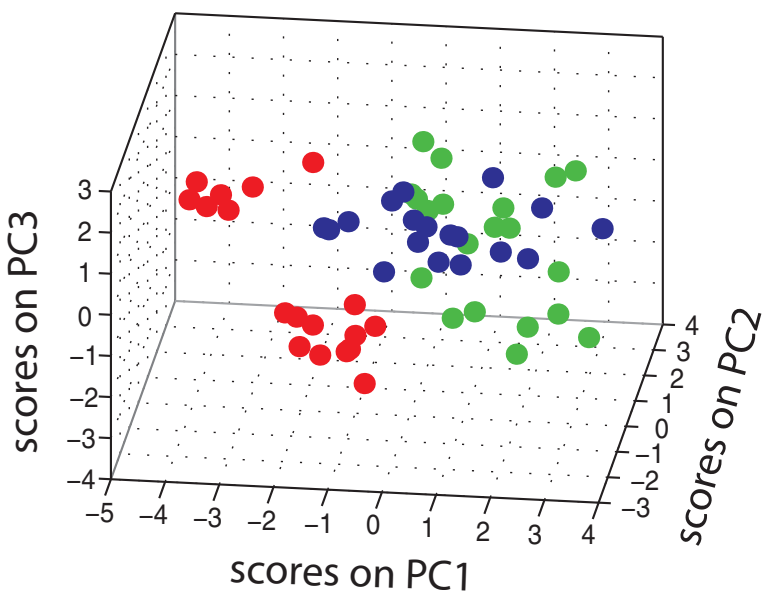

C

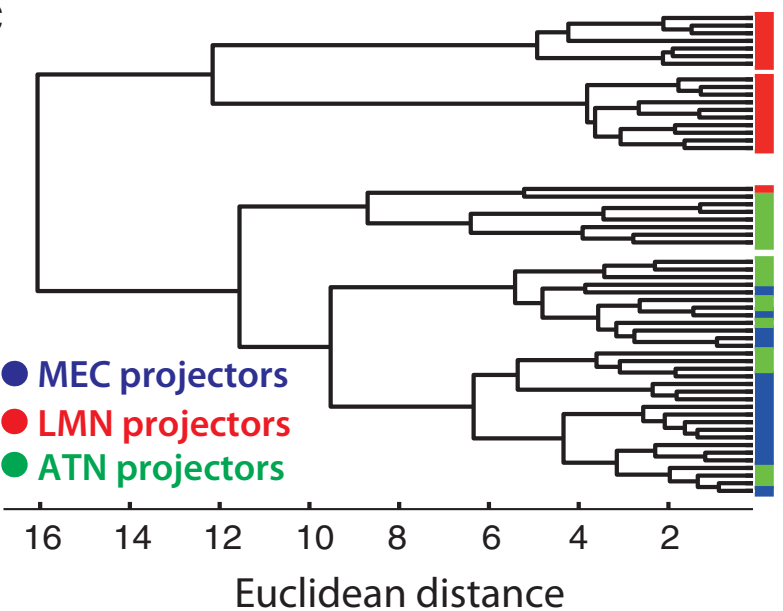

Figure 4. Segregation of MEC projectors (blue), LMN projectors (red) and ATN projectors (green) in PrS. A, Schematic of layering and cell types of the PrS with their preferential projection profiles. Layer II contains neurons targeting the MEC, contralateral PrS, and retrosplenial cortex (Preston-Ferrer et al., 2016). Layer III contains mostly pyramidal MEC projectors. Large pyramidal neurons targeting LMN lie in layer IV. Neurons targeting ATN lie in layer V/VI; their dendrites may or may not reach to layer I (Fig. $2-1) \boldsymbol{B}$, Segregation of projection-specific presubicular neurons based on electrophysiological parameters. Score plot of projecting neurons on PC1, PC2, and PC3 planes. $\boldsymbol{C}$, Cluster analysis of presubicular projecting neurons. 
MEC-projecting neurons are located in superficial layers II and III of the PrS, a population distinct from LMN- or ATN-projecting neurons. Superficial pyramidal cell MEC projectors have a regular spiking firing behavior and are relatively similar to ATN-projecting neurons. A few MEC projectors are in layers IV and V/VI, and those may or may not overlap with LMN- or ATN-projecting neurons. Our results show distinct electrophysiological tuning of presubicular output neurons allowing for pathway-specific transmission of head direction related information.

The three main projection-specific classes of presubicular neurons examined here fit well with a previous classification of presubicular neurons in rats, where neurons were classified based on cellular and morphologic criteria (Simonnet et al., 2013). That study had distinguished regular-firing, small pyramidal neurons in layer II/III of PrS, intrinsically bursting, large pyramidal cells with a prominent sag and rather depolarized membrane potential in layer IV, and heterogeneous regular-firing neurons in layer V/VI, with larger sags than superficial layer cells. The preserved cell layer structure and firing patterns across species, mouse and rat, point to an important functional role of these neuronal subpopulations in the rodent head direction circuit.

Retrograde tracing of MEC-projecting neurons labeled many somata in layer II/III of PrS and a few in deep layers. Our findings confirm previous tracing studies showing that pre- and postsubiculum project bilaterally to the entorhinal cortex (van Groen and Wyss, 1990b; CaballeroBleda and Witter, 1993; van Haeften et al., 1997; Honda and Ishizuka, 2004; Rowland et al., 2013). Specifically, superficial layer III of PrS had been found to send a major axonal projection to ipsilateral MEC layer I/III (CaballeroBleda and Witter, 1993; Honda and Ishizuka, 2004) and a minor projection to MEC layer II (Rowland et al., 2013). Some presubicular layer $\mathrm{V}$ pyramidal cells also send axons to ipsilateral entorhinal cortex, either to layer II and III of MEC (Honda et al., 2011) or to deep layers of MEC (Honda and Ishizuka, 2004). While our results are coherent with the existence of deep-layer presubicular MECprojecting neurons, our physiologic analysis focused on the major projection originating from presubicular layers II/III.

Presubicular layer II and III can be distinguished based on differences in cell body densities, and the distance to the cell sparse layer I. Immunohistochemical labeling, such as calbindin staining, can also help to define layer II (Preston-Ferrer et al., 2016). In our data set of MECprojecting neurons, most were located in layer III. A smaller portion was located close to the interface of layers II and III. In vivo recordings have identified presubicular pyramidal cells in layer III as head direction cells (Peyrache et al., 2015; Tukker et al., 2015; Preston-Ferrer et al., 2016), and their regular firing behavior with little adaptation seems well suited for transmitting directional information to MEC. Functionally, the PrS $\rightarrow$ MEC projection might be key for spatial information generation in the MEC. The nature of the target neurons in MEC remains to be elucidated: do presubicular head direction neurons contact grid cells, border cells or other head direction cells?

A few MEC-projecting neurons (<1\%) were GABAergic, and those cells were strictly located in the ipsilateral PrS, in layer II or III. Previous reports had estimated $20-30 \%$ of MEC projection neurons to be GABAergic (van Haeften et al., 1997). This much higher percentage could be due to a species difference (mouse vs rat), or to a lesser uptake of Retrobeads by interneurons. Also, our presubicular slices were taken at a mid-dorsoventral level, while the GABAergic projection to MEC may be limited to the most dorsal part of the PrS (van Haeften et al., 1997). Presubicular GABAergic neurons may or may not be directionally tuned. Some GABAergic neurons, the fast spiking presubicular interneurons, are sensitive to angular head velocity (Preston-Ferrer et al., 2016). The specific role of inhibition through presubicular MEC projecting interneurons remains to be elucidated.

As noted above, PrS $\rightarrow$ LMN-projecting neurons were exclusively distributed in layer IV of the PrS and PrS $\rightarrow$ ATN-projecting neurons were only found in layer V/VI (Fig. $4 A)$. We thus confirm for mice a previous report from rats, showing that these projection neurons constitute nonoverlapping populations in distinct presubicular layers (Yoder and Taube, 2011). In addition to this anatomic segregation of the two projection-specific subpopulations, we reported for the first time that LMN-projecting neurons and ATN-projecting neurons are also physiologically distinct: LMN-projecting neurons are burst-firing neurons with short latency to spike, while ATN-projecting neurons are regular-firing neurons.

We also find some physiologic diversity within presubicular efferent neuron populations. While the physiologic make-up of a neuronal population might never be entirely identical, the target areas of presubicular projections may not be entirely homogeneous either. Rodent mammillary body and anterior thalamus are subdivided brain structures. Adjacent to the LMN lies the lateral part of the medial mammillary nucleus, which also receives presubicular inputs (van Groen and Wyss, 1990b). It is possible that the two separated LMN-projecting groups in our PCA and clustering analysis correspond to presubicular neurons that contact either of these two subdivisions of the mammillary body. We also observed some diversity for thalamic projection neurons, and indeed, presubicular neurons may target several thalamic subnuclei. The presubicular projection to the thalamus reaches densely the anterodorsal nucleus, and to a lesser degree the anteroventral and laterodorsal nucleus (van Groen and Wyss, 1990a). Possibly the physiologic heterogeneity of presubicular thalamic projecting neurons relates to the heterogeneity of their thalamic target nuclei. An intersectional labeling approach of projection neurons in combination with molecular markers such as transcription factors could further narrow down a defined population of corticothalamic projection neurons (Sürmeli et al., 2015; Woodworth et al., 2016).

Presubicular LMN-projecting neurons may be the preferential route for visual information to update the subcortical head direction signal (Yoder and Taube, 2011; Yoder 
et al., 2015; Bicanski and Burgess, 2016). Visual cortex sends direct projections to the superficial layers of PrS (Vogt and Miller, 1983) and also indirectly via the retrosplenial cortex (Sugar and Witter, 2016). Presubicular layer IV pyramidal neurons could receive these inputs directly, given their prominent dendritic arborization that extends in superficial layers (Yoder and Taube, 2011; Simonnet et al., 2013). We suggest that the fast integrative properties and the intrinsic burst firing behavior of layer IV PrS $\rightarrow$ LMN-projecting neurons favor fast and reliable transfer of information. Indeed, the visual update of the head direction signal becomes effective within a very short latency $(\sim 80 \mathrm{~ms})$ in thalamus (Zugaro et al., 2003), suggesting that the synaptic transmission from visual cortex to ATN should be very fast, either via PrS $\rightarrow$ LMN $\rightarrow$ ATN or directly via the PrS $\rightarrow$ ATN projection. Efficient excitatory drive might be rapidly sent in parallel pathways, to the LMN, and to neurons projecting to ATN, providing convergent information from the PrS and LMN to update the head direction signal in thalamus.

While presubicular head direction cells signal the current head direction, LMN (Stackman and Taube, 1998) and ATN (Goodridge and Taube, 1997) head direction cells anticipate future head direction. The anticipatory time interval depends on the frequency of visual updates: feedback should act intermittently rather than continuously and, modeling studies suggest, visual update should best be delivered at low frequencies ( $<1 \mathrm{~Hz}$; van der Meer et al., 2007). Single spike or intrinsically burst firing of presubicular LMN projecting layer IV neurons may provide the necessary sparse coding.

While in vivo head direction cells were recorded across superficial and deep layers of PrS (Boccara et al., 2010), we revealed for the first time different physiologic signatures of presubicular cells that project to key areas of the head direction system, namely the upstream LMN and ATN, and the downstream MEC. The presubicular projection to the LMN relays visual information to the head direction system and may enhance head direction signal stability and accuracy (Yoder et al., 2015). The bursting nature of PrS $\rightarrow$ LMN-projecting neurons ensures that visual feedback is sent sparsely but efficiently with little delay to the subcortical generating circuit of the head direction signal.

\section{References}

Allen GV, Hopkins DA (1989) Mamillary body in the rat: topography and synaptology of projections from the subicular complex, prefrontal cortex, and midbrain tegmentum. J Comp Neur 286:311336. CrossRef Medline

Bassett JP, Tullman ML, Taube JS (2007) Lesions of the tegmentomammillary circuit in the head direction system disrupt the head direction signal in the anterior thalamus. J Neurosci 27:75647577. CrossRef Medline

Bicanski A, Burgess N (2016) Environmental anchoring of head direction in a computational model of retrosplenial cortex. J Neurosci 36:11601-11618. CrossRef Medline

Blair HT, Cho J, Sharp PE (1998) Role of the lateral mammillary nucleus in the rat head direction circuit: a combined single unit recording and lesion study. Neuron 21:1387-1397. Medline

Boccara CN, Sargolini F, Thoresen VH, Solstad T, Witter MP, Moser El, Moser M-B (2010) Grid cells in pre- and parasubiculum. Nat Neurosci 13:987-994. CrossRef Medline
Caballero-Bleda M, Witter MP (1993) Regional and laminar organization of projections from the presubiculum and parasubiculum to the entorhinal cortex: an anterograde tracing study in the rat. $J$ Comp Neur 328:115-129. CrossRef

Clark BJ, Taube JS (2012) Vestibular and attractor network basis of the head direction cell signal in subcortical circuits. Front Neural Circuits 6:7. CrossRef Medline

Connors BW, Gutnick MJ (1990) Intrinsic firing patterns of diverse neocortical neurons. Trends Neurosci 13:99-104. Medline

Golowasch J, Thomas G, Taylor AL, Patel A, Pineda A, Khalil C, Nadim F (2009) Membrane capacitance measurements revisited: dependence of capacitance value on measurement method in nonisopotential neurons. J Neurophysiol 102:2161-2175. CrossRef Medline

Gonzalo-Ruiz A, Alonso A, Sanz JM, Llinás RR (1992) Afferent projections to the mammillary complex of the rat, with special reference to those from surrounding hypothalamic regions. J Comp Neur 321:277-299. CrossRef Medline

Goodridge JP, Taube JS (1997) Interaction between the postsubiculum and anterior thalamus in the generation of head direction cell activity. J Neurosci 17:9315-9330. Medline

Hafting T, Fyhn M, Molden S, Moser M-B, Moser El (2005) Microstructure of a spatial map in the entorhinal cortex. Nature 436:801806. CrossRef Medline

Honda Y, Furuta T, Kaneko T, Shibata H, Sasaki H (2011) Patterns of axonal collateralization of single layer $\mathrm{V}$ cortical projection neurons in the rat presubiculum. J Comp Neur 519:1395-1412. CrossRef

Honda Y, Ishizuka N (2004) Organization of connectivity of the rat presubiculum: I. Efferent projections to the medial entorhinal cortex. J Comp Neur 473:463-484. CrossRef Medline

Ishizuka N (2001) Laminar organization of the pyramidal cell layer of the subiculum in the rat. J Comp Neur 435:89-110. Medline

Jones BF, Witter MP (2007) Cingulate cortex projections to the parahippocampal region and hippocampal formation in the rat. Hippocampus 17:957-976. CrossRef Medline

Mathon B, Nassar M, Simonnet J, Le Duigou C, Clemenceau S, Miles R, Fricker D (2015) Increasing the effectiveness of intracerebral injections in adult and neonatal mice: a neurosurgical point of view. Neurosci Bull 31:685-696. CrossRef Medline

Nassar M, Simonnet J, Lofredi R, Cohen I, Savary E, Yanagawa Y, Miles R, Fricker D (2015) Diversity and overlap of parvalbumin and somatostatin expressing interneurons in mouse presubiculum. Front Neural Circuits 9:1-19. CrossRef Medline

O'keefe J, Nadel L (1978) The hippocampus as a cognitive map, pp 1-296. Oxford: Oxford University Press.

Peyrache A, Lacroix MM, Petersen PC, Buzsáki G (2015) Internally organized mechanisms of the head direction sense. Nat Neurosci 18:569-575. CrossRef Medline

Preston-Ferrer P, Coletta S, Frey M, Burgalossi A (2016) Anatomical organization of presubicular head-direction circuits. eLife 5.pii: e14592. CrossRef

Romesburg HC (1984) Cluster analysis for researchers. Belmont: Lulu Press.

Rowland DC, Weible AP, Wickersham IR, Wu H, Mayford M, Witter MP, Kentros CG (2013) Transgenically targeted rabies virus demonstrates a major monosynaptic projection from hippocampal area CA2 to medial entorhinal layer II neurons. J Neurosci 33:1488914898. CrossRef

Simonnet J, Eugène E, Cohen I, Miles R, Fricker D (2013) Cellular neuroanatomy of rat presubiculum. Eur J Neurosci 37:583-597. CrossRef Medline

Stackman RW, Taube JS (1997) Firing properties of head direction cells in the rat anterior thalamic nucleus: dependence on vestibular input. J Neurosci 17:4349-4358. Medline

Stackman RW, Taube JS (1998) Firing properties of rat lateral mammillary single units: head direction, head pitch, and angular head velocity. J Neurosci 18:9020-9037. Medline

Sugar J, Witter MP (2016) Postnatal development of retrosplenial projections to the parahippocampal region of the rat. eLife 5:1-58. CrossRef 
Sürmeli G, Marcu DC, McClure C, Garden DLF, Pastoll H, Nolan MF (2015) Molecularly defined circuitry reveals input-output segregation in deep layers of the medial entorhinal cortex. Neuron 88: 1040-1053.

Taube JS (2007) The head direction signal: origins and sensorymotor integration. Annu Rev Neurosci 30:181-207. CrossRef Medline

Tsiola A, Hamzei-Sichani F, Peterlin Z, Yuste R (2003) Quantitative morphologic classification of layer 5 neurons from mouse primary visual cortex. J Comp Neur 461:415-428. CrossRef Medline

Tukker JJ, Tang Q, Burgalossi A, Brecht M (2015) Head-directional tuning and theta modulation of anatomically identified neurons in the presubiculum. J Neurosci 35:15391-15395. CrossRef Medline

van der Meer MAA, Knierim JJ, Yoganarasimha D, Wood ER, van Rossum MCW (2007) Anticipation in the rodent head direction system can be explained by an interaction of head movements and vestibular firing properties. J Neurophysiol 98:1883-1897. CrossRef

van Groen T, Wyss JM (1990a) The postsubicular cortex in the rat: characterization of the fourth region of the subicular cortex and its connections. Brain Res 529:165-177. Medline

van Groen T, Wyss JM (1990b) The connections of presubiculum and parasubiculum in the rat. Brain Res 518:227-243. Medline

van Haeften T, Wouterlood FG, Jorritsma-Byham B, Witter MP (1997) GABAergic presubicular projections to the medial entorhinal cortex of the rat. J Neurosci 17:862-874.
Vogt BA, Miller MW (1983) Cortical connections between rat cingulate cortex and visual, motor, and postsubicular cortices. J Comp Neur 216:192-210. CrossRef Medline

Ward JH Jr (1963) Hierarchical grouping to optimize an objective function. J Am Stat Assoc 58:236-244. CrossRef

Winter SS, Clark BJ, Taube JS (2015) Spatial navigation. Disruption of the head direction cell network impairs the parahippocampal grid cell signal. Science 347:870-874. CrossRef Medline

Woodworth MB, Greig LC, Liu KX, Ippolito GC, Tucker HO, Macklis JD (2016) Ctip1 regulates the balance between specification of distinct projection neuron subtypes in deep cortical layers. Cell Rep 15:999-1012.

Yoder RM, Peck JR, Taube JS (2015) Visual landmark information gains control of the head direction signal at the lateral mammillary nuclei. J Neurosci 35:1354-1367. CrossRef Medline

Yoder RM, Taube JS (2011) Projections to the anterodorsal thalamus and lateral mammillary nuclei arise from different cell populations within the postsubiculum: implications for the control of head direction cells. Hippocampus 21:1062-1073. CrossRef Medline

Yoder RM, Taube JS (2014) The vestibular contribution to the head direction signal and navigation. Front Integr Neurosci 8:32. CrossRef Medline

Zugaro MB, Arleo A, Berthoz A, Wiener SI (2003) Rapid spatial reorientation and head direction cells. J Neurosci 23:3478-3482. 